\title{
Performance of baited traps used as control tools for the invasive hornet Vespa velutina and their impact on non- target insects
}

\author{
Sandra V. Rojas-Nossa ${ }^{1,2}$, Noelia NovoA ${ }^{3}$, Antonio SERrano ${ }^{3}$, \\ María CALVIÑO-CANCElA ${ }^{2}$ \\ ${ }^{1}$ Asociación Gallega de Apicultura (AGA), Rua Basilio Carril s/n, 15819, Santiago de Compostela, La Coruña, Spain
${ }^{2}$ Faculty of Biology, University of Vigo, 36310, Vigo, Pontevedra, Spain
}

Received 2 February 2018 - Revised 15 August 2018 - Accepted 12 October 2018

\begin{abstract}
The efficiency and selectiveness of baited traps to control the invasive hornet Vespa velutina is often questioned. Comparative assessments are needed to improve control plans and reduce the impact on honeybees and entomofauna. Our aims were to study the performance of traps and baits, to identify environmental conditions that affect capture rates and to identify the groups of insects affected by trapping. During spring in 2016, three types of trap and baits in a full factorial design were tested. Vespa velutina accounted for less than $1 \%$ of all captures, reflecting the low selectiveness of the method. The trap design and its location are decisive aspects to determine the capture rates of $V$. velutina queens. All trap-bait combinations captured a very high quantity of dipterans, native hymenopterans, and lepidopterans. High capture rates of insect groups which are not common prey of $V$. velutina reflect that the method constitutes an additional threat on native insects.
\end{abstract}

apiculture / Apis mellifera / invasive species / pest management tools / yellow-legged hornet

\section{INTRODUCTION}

Vespa velutina (Lepeletier) is a social hornet native to Eastern Asia that has successfully invaded several countries of Europe and Asia (Choi et al. 2012; Monceau et al. 2014; Ueno 2014). In Europe, first records situate the invasion focus in central France short before 2005 (Haxaire et al. 2006; Rortais et al. 2010). By 2012, it had invaded an area of $360,000 \mathrm{~km}^{2}$ at a speed of $100 \mathrm{~km} /$ year (Rome et al. 2015) and by 2017, it had spread over

Electronic supplementary material The online version of this article (https://doi.org/10.1007/s13592-018-0612-0) contains supplementary material, which is available to authorized users.

Corresponding author: S. Rojas-Nossa, srojas@uvigo.es

Manuscript Editor: Peter Rosenkranz several countries of Central and Eastern Europe including France, Spain, Portugal, Belgium, Italy, Germany, the UK, the Netherlands, and Switzerland (Witt 2015; EPPO 2016; A.C.M. Cornelissen Pers. Comm.; Sciences Switzerland 2017; INPN 2018). Suitability models suggest that its ecological niche is limited by low temperatures, precipitation regimes, and land use, making large areas of the Iberian Peninsula, central Europe, the Balkan Peninsula, and Turkey appropriate for the colonization of the species (Villemant et al. 2011a; Bessa et al. 2016).

The invasion of $V$. velutina constitutes a multiple threat for biodiversity, economic activities, and human health (Monceau et al. 2014). Adults are predators of a wide diversity of arthropods, including bees, social wasps, and flies, hunted and carried to the nest to provide protein for the larvae (Tan et al. 2007; Perrard et al. 2009; Rome et al. 
2011b). They specialize in hunting honeybees by waiting for prey in front of the beehives (Monceau et al. 2013a). Hunting activity in honeybee hives could be so intense that apiculture results severely affected by the invasion of this social insect. Although far from the nest hornets seem not to be particularly aggressive against humans, workers defend the nest when people approaches less than 5 m (Perrard et al. 2009; de Haro et al. 2010). Some attacks occur when people try to destroy the nest without proper tools and techniques (de Haro et al. 2010) or when nests are accidentally disturbed, e.g., during vegetation clearing activities. Despite the increase in the population of the invasive hornet, records of envenomation by hymenopterans in France remained constant between 2009 and 2013 (Viriot et al. 2015). The most common clinical manifestations after stinging are local reactions (Ciron et al. 2015; Tabar et al. 2015). However, under particular circumstances, people can suffer immediate hypersensitivity or massive envenomation with severe consequences (Fitzgerald and Flood 2006; de Haro et al. 2010; Ciron et al. 2015; Liu et al. 2015).

The annual cycle of $V$. velutina begins with queens emerging of hibernation and beginning the foundation from new colonies in early spring (Monceau et al. 2014). The period since the queen initiates the construction of the nest until the day before the first worker adult emerges is named the "queen colony phase" (Archer 2010). Colonies are highly vulnerable during this period because their success relies mainly in the energy, performance, and survivorship of a single individual, the young queen or "foundress" (Spradbery 1973; Archer 2010). Hence, it is considered a particularly suitable time for trapping, because for each captured queen, there is a potential colony being destroyed (Spradbery 1973; Haxaire and Villemant 2010).

The social and economic implications of the invasion and the high colonization ability of $V$. velutina have fostered massive trapping campaigns, commonly supported by beekeepers and local governments, with the aim of reducing the population and diminishing its impacts. Bait trapping is one of the most used tools to control wasps and hornets (Toft and Harris 2004; Demichelis et al. 2014). Nevertheless, the effectiveness of spring trapping campaigns has been questioned for several reasons. First, because the capture rate is low in comparison with the estimated quantity of queens produced during the former season (Monceau et al. 2012). Also because recolonization from adjacent areas is probably high (Monceau and Thiéry 2017), particularly considering that the invasion in Europe was caused by one single female and that the spread rate is around $100 \mathrm{~km}$ per year (Arca et al. 2015; Robinet et al. 2017). In addition, a high number of non-target animals are commonly captured in baited traps. Several evidences indicate that this low selectiveness of the method has important impacts on the entomofauna threatening native populations of insects (Dauphin and Thomas 2009; Haxaire and Villemant 2010; Monceau et al. 2012, 2014; Goldarazena et al. 2015; Monceau and Thiéry 2017). Together, high recolonization rates and the low selectiveness of baited traps make trapping campaigns ineffective in terms of balance between the benefits to control the invasive population and the environmental costs (Monceau and Thiéry 2017).

Traps (either commercial or craft-made) consist of a container in the form of a vessel, dome, or box with one or more entrances that hinder the exit of insects and a chamber where they die of exhaustion and/or drowning. Baits consists mainly of sugary or protein substances attractive to social vespids or chemical compounds similar to the volatiles released by fruits or animals in decomposition, with an alcoholic component added as a repellent for honey bees (Landolt 1998; Wegner and Jordan 2005; Landolt et al. 2007; Demichelis et al. 2014). Both the characteristics of the trap and the type of bait are expected to affect the effectiveness and selectiveness of trapping campaigns. In addition to the features of traps and baits, diverse environmental factors can influence the effectiveness of baited traps. Factors such as land cover, habitat structure, or human disturbance are likely to affect both abundance and foraging preferences of $V$. velutina, increasing the chances to capture them in particular areas. For instance, one of the most frequent prey of $V$. velutina is the honeybee (Perrard et al. 2009); thus, traps placed next to apiaries may have higher chances to capture hornets (Rome et al. 2011a). 
On the other hand, evidence suggests that nests are mainly placed in trees near rivers or streams (Bessa et al. 2016 but see Fournier et al. 2017), which might increase capture rates in the proximity of water bodies.

A better knowledge of the performance of different methods is essential for improving the success of spring trapping campaigns and to reduce their detrimental effects on the native entomofauna. With this aim, the objectives in this work are as follows: (a) to study and compare the capture rate and selectiveness of traps and baits commonly used as control methods; (b) to study the environmental conditions that affect capture rates of queens of $V$. velutina in baited traps; and (c) to identify the groups of insects affected by trapping campaigns.

\section{MATERIALS AND METHODS}

\subsection{Tested traps and baits}

The performance of three different kinds of traps filled with three commonly used baits was compared. In total, nine treatments (each combination of trap $\times$ bait) were tested. Tested traps included two commercial traps: Avispa'clac $(\subset$ (PROTECTA SAS, Le Thor, France) and VétoPharma ${ }^{\circ}$ (Véto-Pharma, Villebon-sur-Yvette, France), and one home-made trap (Figure 1). The Avispa'clac $\subset$ trap (A trap onwards) consists of a green container covered with dome-shaped transparent plastic, with one entrance $(60-\mathrm{mm}$ diameter) placed in the bottom of the trap, in the center of the base (Figure 1a). The Véto-Pharma $(9$ trap (V trap onwards) consists of a plastic cup of translucent-yellow color with a black lid with two opposite entrances (14-mm diameter) and a black plastic cover that prevents the entrance of rain and produces a tunnel effect (Figure 1b). Home-made traps (H trap onwards) were made with transparent plastic 1.5-1 water bottles, by cutting off the upper part (funnel) and sticking it upside down into the bottom part of the bottle (shaft). Small holes of $5 \mathrm{~mm}$ are made in the lateral walls to provide an escape for small insects. Another piece of plastic was placed over the trap as a roof to prevent rain water from entering the trap (Figure 1c). Regarding baits, we tested two commercial types: Avispa'clac $@$ (PROTECTA SAS, Le Thor, France) and Véto-Pharma $\odot$ (VétoPharma, Villebon-sur-Yvette, France), and one home-made bait. The Avispa'clac(C) bait (A bait onwards) was prepared by mixing $125 \mathrm{ml}$ attractant and $250 \mathrm{ml}$ water. The Avispa'clac@ attractant contains an extract of food flavorings and acetic acid, according to the information provided by the manufacturer. The Véto-Pharma $\odot$ bait (V bait onwards) was prepared by mixing $10 \mathrm{ml}$ attractant, $50 \mathrm{~g}$ sugar, and $200 \mathrm{ml}$ water. The VétoPharma $\odot$ attractant contains water, ethanol, plant extracts, and natural active compounds
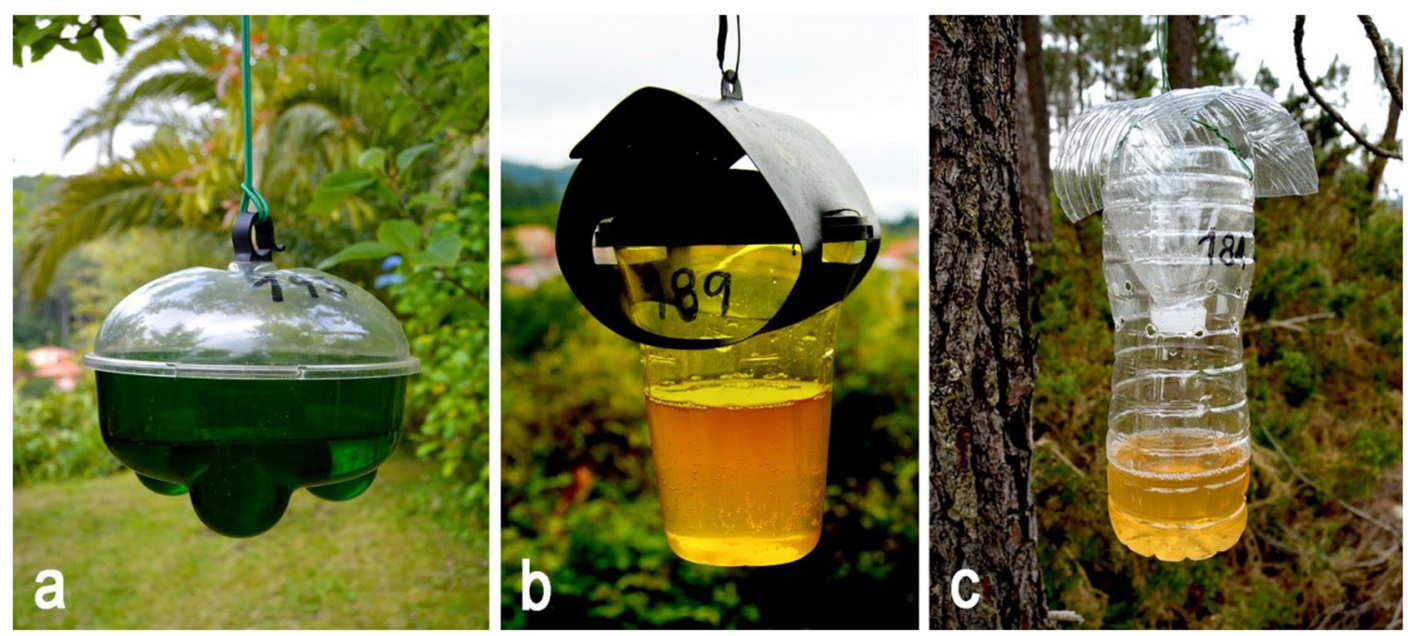

Figure 1. The performance of tree kind of traps was evaluated: Avispa'clack (a), Véto-pharma (b), and Home-made trap (c). 
accordingly to the information provided by the manufacturer in the product label. The homemade bait ( $\mathrm{H}$ bait onwards) was prepared by mixing $100 \mathrm{ml}$ of black beer, $100 \mathrm{ml}$ of white wine, $50 \mathrm{ml}$ of cranberry juice, and $50 \mathrm{~g}$ of sugar. Because the A trap has a bigger chamber, the quantity of bait in the treatments using this trap was 1.5 times higher than other treatments.

\section{SAMPLING METHOD}

Traps were placed hanging on trees or poles at $1.50 \mathrm{~m}$ over the ground (Figure 1). Baited traps were placed from 1 April to 30 June 2016. Every 14-15 days, the traps were emptied. All individuals captured were preserved in vials with ethanol $70 \%$ and the bait was renewed.

A total of 180 traps and baits were randomly distributed among volunteer beekeepers of $21 \mathrm{mu}-$ nicipalities (Table I and Figure 2) throughout the invaded area of Galicia, Spain (nine treatments, two replicates of each treatment per "Delegation of Galician Beekeeping Association"). Because in each municipality, there were a different number of volunteers, the number of sites and traps differed among municipalities. Treatments were randomly distributed among sites. When different treatments were placed in the same site, the distance between traps was $>20 \mathrm{~m}$. The final number of samples was unbalanced because in some cases, the samples were partially collected (not for the whole 3 months). Also, in few cases, the trap was fallen, damaged, or the entrance was blocked by snails failing to capture any insect during one sampling period. These samples were discarded for analysis.

Additionally, because the aim was to compare the capture rates of queens during spring, it was necessary to identify the periods when only queens were trapped and separate these samples from those in which the first workers appeared. To do this, $200 \mathrm{~V}$. velutina individuals from the samples of the whole sampling period were randomly selected. The exemplars were characterized morphologically to determine the end of the queen colony phase and the presence of individuals of the first cohort of workers in traps. The threshold of $4.5 \mathrm{~mm}$ for mesoscutum width was used to differentiate queens from workers, so that individuals with a wider mesoscutum were identified as queens (Pérez-de-Heredia et al. 2017). This characterization allowed determining that first workers are more frequent in June in most localities. Therefore, only samples obtained from 1 April to 31 May with complete data for all environmental variables were included in the analysis. Finally, a total of 253 samples were analyzed.

At the laboratory, all individuals collected in traps were determined and counted at the order level, except in the case of Vespa crabro, Vespa velutina, and Apis mellifera which were identified and counted at the species level. Other individuals within Hymenoptera were identified as Apoidea, Vespoidea, or Formicidae.

\subsection{Environmental factors}

To analyze the effect of environmental factors for the capture of $V$. velutina , traps were randomly placed. Then, environmental conditions for each trap were characterized according to the land use and the proximity to apiaries and bodies of water. Three categories of land use were selected: (a) urban areas, (b) rural areas, composed by an agricultural mosaic with scattered houses, orchards, mixed crops, and garden plants, and (c) forest areas with predominance of Pinus sp., Eucalyptus sp., and Quercus sp. trees and a understory often composed by Ulex sp. and several species of Ericaceae. The proximity to apiaries and bodies of water was characterized by a binary variable (yes/ no) according to the following criteria: Traps were considered to be near apiaries when the distance was $\leq 50 \mathrm{~m}$ and near to bodies of water when the distance was $\leq 2 \mathrm{~km}$ to streams, rivers, or lakes.

\subsection{Data analysis}

To compare the performance of treatments, the rate of $V$. velutina individuals captured per trap per day was estimated. Selectiveness was assessed as the capture rate of $V$. velutina /capture rate of other insects per trap per day.

The effect of the trap, bait, and location on the capture rate and selectiveness of trapping $V$. velutina and non-target taxa was analyzed by fitting generalized linear mixed models (GLMM) 
Table I. Number of samples analyzed for each site (municipality) and category of environmental factor. *Proximity of the traps to apiaries was classified as yes for traps paced $\leq 50 \mathrm{~m}$. ${ }^{\S}$ Proximity to bodies of fresh water (streams, rivers, or lakes) $\leq 2 \mathrm{~km}$.

\begin{tabular}{|c|c|c|c|c|c|c|c|}
\hline \multirow[t]{2}{*}{ Site } & \multicolumn{3}{|c|}{ Land use } & \multicolumn{2}{|c|}{ Apiary* } & \multicolumn{2}{|c|}{ Bodywater $^{\S}$} \\
\hline & Forest & Rural & Urban & Yes & No & Yes & No \\
\hline Arteixo & & 27 & & 27 & & 27 & \\
\hline Baiona & & 6 & & 6 & & 2 & 4 \\
\hline Boiro & & 11 & & 8 & 3 & 9 & 2 \\
\hline Capela & & 2 & & & 2 & 2 & \\
\hline Cariño & & 2 & & & 2 & 2 & \\
\hline Culleredo & & & 6 & & 6 & 6 & \\
\hline Gondomar & & 7 & & 5 & 2 & 2 & 5 \\
\hline Laracha & 9 & 23 & & 10 & 22 & 32 & \\
\hline Mañón & & 12 & & & 12 & 10 & 2 \\
\hline Moaña & & 43 & & & 43 & 13 & 30 \\
\hline Mos & & 3 & & 3 & & 3 & \\
\hline Muros & & 2 & & 2 & & & 2 \\
\hline Oia & 2 & 1 & & 3 & & 3 & \\
\hline Oleiros & 6 & 4 & 22 & 4 & 28 & 16 & 16 \\
\hline Ortigueira & & 26 & & 10 & 16 & 16 & 10 \\
\hline Salceda de Caselas & & 8 & & 4 & 4 & 8 & \\
\hline San Sanduriño & & 8 & & & 8 & 8 & \\
\hline Tui & & 11 & & 11 & & 11 & \\
\hline Valdoviño & & 1 & & 1 & & 1 & \\
\hline Vicedo & & 4 & & & 4 & 1 & 3 \\
\hline Vigo & & 7 & & & 7 & & 7 \\
\hline Total & 17 & 208 & 28 & 62 & 191 & 172 & 81 \\
\hline
\end{tabular}

using the type of trap and bait (and its interaction), the proximity to apiaries, to bodies of water, and the land use as fixed effects. Since each trap was used repeatedly to collect samples throughout the study period, the identity of traps was included as a random factor into the model to control for pseudoreplication. Response variables either the amount of individuals of $V$. velutina captured (when evaluating capture rate) or the proportion of $V$. velutina out of the total amount of insects captured (when evaluating selectiveness) were included. After checking the data distributions, the negative binomial error distribution and the logratio link function for the amount of $V$. velutina captured were used. The binomial error distribution with logit link function was used for the proportion of $V$. velutina out of the total amount of insects captured (selectiveness). To select the best model for capture rate and selectiveness of trapping, we fitted several models including interactions between predictors. Because we were particularly interested in the effect of environmental variables and performance of the interaction of traps and baits, we maintained these basic predictors (trap, bait, land use, proximity to apiaries, proximity to bodywaters) and the interaction (trap $\times$ bait) in all fitted models. Per response variable (capture rate of $V$. velutina and selectiveness), we fitted models including all possible interactions between environmental variables, the type of trap, and the type of bait following suggestions by Burnham and Anderson (2002). Models including the interaction land use $\times$ proximity to bodywaters were not fitted because of the low number of 


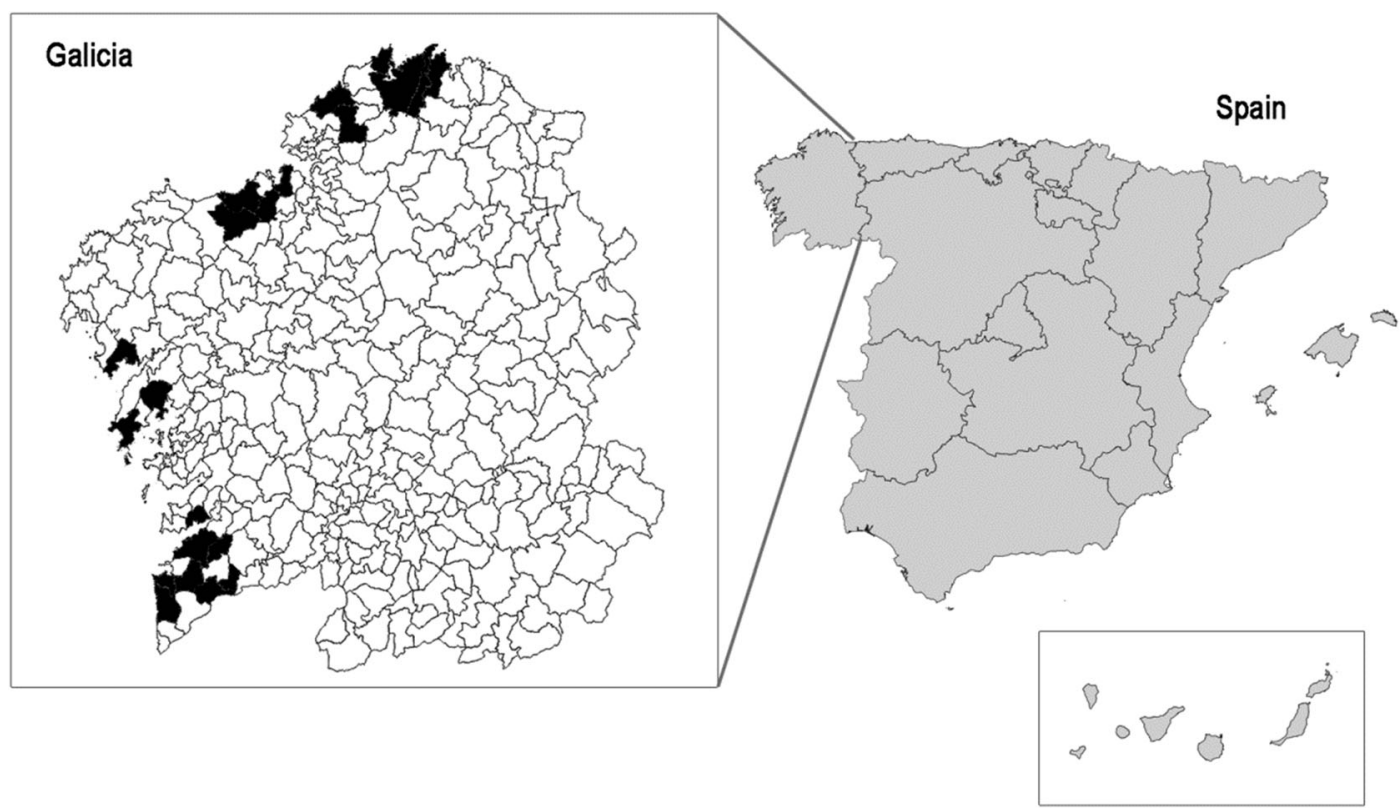

Figure 2. The study was performed in the coastal area of Galicia, Northwest Spain.

samples obtained for traps placed into the forest that were at the same time far from bodywaters. The top three performing models for each response variable are shown in Supplementary Material Tables S1 and S2. We used Akaike's information criteria to compare the models and select the best performing model for each response variable (performance and selectiveness for the capture of $V$. velutina). Models were fitted in $\mathrm{R}$ software using the packages MASS version 7.347 (Venables and Ripley 2002) and glmmADMB version 0.8.3.3 (Skaug et al. 2011).

\section{RESULTS}

\subsection{Capture rate of baited traps}

The average number of captured $V$. velutina individuals was 0.37 individuals per trap per day. The capture frequency of the target species was relatively low $(0.55$, see Table II), meaning that only one half of the traps placed in spring in areas invaded achieve the goal of trapping $V$. velutina queens. The type of trap had a significant effect on the quantity of $V$. velutina individuals captured (Table III). A-type traps had the highest capture rate (Figure 3a), which was 2.5 times higher on average than that of $\mathrm{V}$ traps, and 12.7 times higher than that of $\mathrm{H}$ traps. The capture rate of $\mathrm{V}$ traps was 5.2 times higher on average than that of $\mathrm{H}$ traps. Neither the type of bait nor the interaction between trap and bait had significant effects on the capture rate of the invasive hornet (Table III).

\subsection{Selectiveness of baited traps}

V. velutina accounted for $0.90 \%$ of all captures (Table II). All treatments captured a high number of individuals of non-target species per trap for each $V$ velutina captured (mean $=134.6)$. The selectiveness of traps was significantly affected by the type of trap (Table IV). A traps were the most selective (Figure $3 \mathrm{~b}$ ), with an average 2.5 and 5.6 times higher selectiveness than $\mathrm{V}$ traps and $\mathrm{H}$ traps, respectively. V traps, on their part, had higher selectiveness than $\mathrm{H}$ traps (2.2 times higher on average).

\subsection{Environmental factors}

The land use and the proximity to apiaries had significant effects on the capture rates of the invasive hornet (Table III). Traps placed in the forest and 
Table II. Percentage, mean, and frequency of individuals captured in baited traps of the invasive target species (Vespa velutina) and non-target insects. "Excluding A. mellifera. "Excluding V. velutina, V. crabro, and Formicidae. ${ }^{\S}$ Frequency calculated as number of samples with presence of the species (or group)/253 (samples analyzed).

\begin{tabular}{lccl}
\hline Insects captured & $\begin{array}{l}\text { \% of the total captured } \\
\text { individuals }(n=144,368)\end{array}$ & $\begin{array}{l}\text { Mean per sample } \pm \\
\text { standard deviation } \\
(\S \text { frequency) }\end{array}$ & $\begin{array}{l}\text { Taxa hunted by V. velutina } \\
\text { according to a previous study } \\
\text { (Villemant et al., 2011a) }\end{array}$ \\
\hline $\begin{array}{l}\text { Vespa velutina } \\
\text { Non-target taxa }\end{array}$ & 0.90 & $5.13 \pm 11.25(0.55)$ & \\
Diptera & 92.65 & $528.67 \pm 578.67(1)$ & Yes \\
Hymenoptera & & & Yes \\
Apoidea & 0.08 & $6.13 \pm 8.13(0.06)$ & Yes \\
Apis mellifera & 0.17 & $0.96 \pm 4.02(0.25)$ & \\
Vespoideat & 0.28 & $3.69 \pm 5.87(0.43)$ & \\
Vespa crabro & 0.16 & $5.61 \pm 5.42(0.16)$ & \\
Formicidae & 3.82 & $82.25 \pm 242.77(0.26)$ & \\
Lepidoptera & 1.20 & $12.45 \pm 18.64(0.55)$ & \\
Coleoptera & 0.66 & $12.63 \pm 27.56(0.30)$ & \\
Blattodea & 0.02 & $3.25 \pm 5.18(0.03)$ & Yes \\
Aracnoidea & 0.02 & $1.65 \pm 1.69(0.07)$ & \\
Dermaptera & 0.01 & $1.67 \pm 1.72(0.05)$ & \\
Other groups & 0.03 & $0.16 \pm 1.20(0.05)$ & \\
\hline
\end{tabular}

rural areas and those near apiaries captured more individuals of the target species (Figure $4 a, b$ ). The capture rate in the forest was 1.2 and 2.6 higher than in rural and urban areas respectively, while traps placed in rural areas captured 2.1 times more $V$ velutina individuals than those placed in urban areas. The capture rate of traps was 3.7 higher when placed next to apiaries than far from them.

Table III. Results from (GLMM) analysis of the capture rate of $V$. velutina with nine treatments (three types of trap combined with three baits).

\begin{tabular}{lccc}
\hline Factor & d.f. & $\begin{array}{l}\text { Deviance } \\
\left(\chi^{2}\right)\end{array}$ & $p$ value \\
\hline Trap & 2 & 31.63 & $<0.001^{* *}$ \\
Bait & 2 & 3.71 & 0.157 \\
Trap:Bait & 4 & 1.54 & 0.819 \\
Proximity to apiaries & 1 & 9.51 & $0.002^{*}$ \\
$\begin{array}{l}\text { Proximity to } \\
\text { bodywaters }\end{array}$ & 1 & 0.26 & 0.608 \\
Land use & 3 & 14.34 & $<0.001^{* *}$ \\
\hline
\end{tabular}

\subsection{Native insects affected by trapping campaigns}

Among non-target insects captured, Diptera were the most frequent, accounting for $92.65 \%$ of all captures (Table II). Other frequent taxa captured were Hymenoptera (particularly Formicidae, Vespula sp., Apis mellifera, and Vespa crabro), Lepidoptera and Coleoptera. The type of trap had a significant effect on the capture rate of Diptera $\left(X^{2}=15.12, p<0.001, \mathrm{df}=2\right.$ Figure $\left.3 \mathrm{c}\right)$, A. mellifera $\left(X^{2}=9.71, p=0.008, \mathrm{df}=2\right.$ Figure 3d), Vespoidea $\left(X^{2}=19.40, p<0.001, \mathrm{df}=\right.$ 2 Figure 3e), Formicidae $\left(X^{2}=14.40, p<0.001\right.$, $\mathrm{df}=2$ Figure $3 \mathrm{~g})$, and Lepidoptera $\left(X^{2}=51.62\right.$, $p<0.001, \mathrm{df}=2$ Figure $3 \mathrm{~h}$ ). The latter was also the only group affected by the type of bait $\left(X^{2}=\right.$ 7.13, $p=0.029$; $\mathrm{df}=2$ ). Among environmental variables, the GLM revealed that the land use affected captures of Vespoidea $\left(X^{2}=6.69, p=\right.$ 0.035 , df $=2$ Figure 4c), V. crabro $\left(X^{2}=6.14\right.$, $p=0.047, \mathrm{df}=2$ Figure $4 \mathrm{~d})$, Formicidae $\left(X^{2}=\right.$ 17.71, $p<0.001 ; \mathrm{df}=2$ Figure 4e), and Lepidoptera $\left(X^{2}=13.79, p=0.001 ; \mathrm{df}=2\right.$ Figure $\left.4 \mathrm{f}\right)$. 

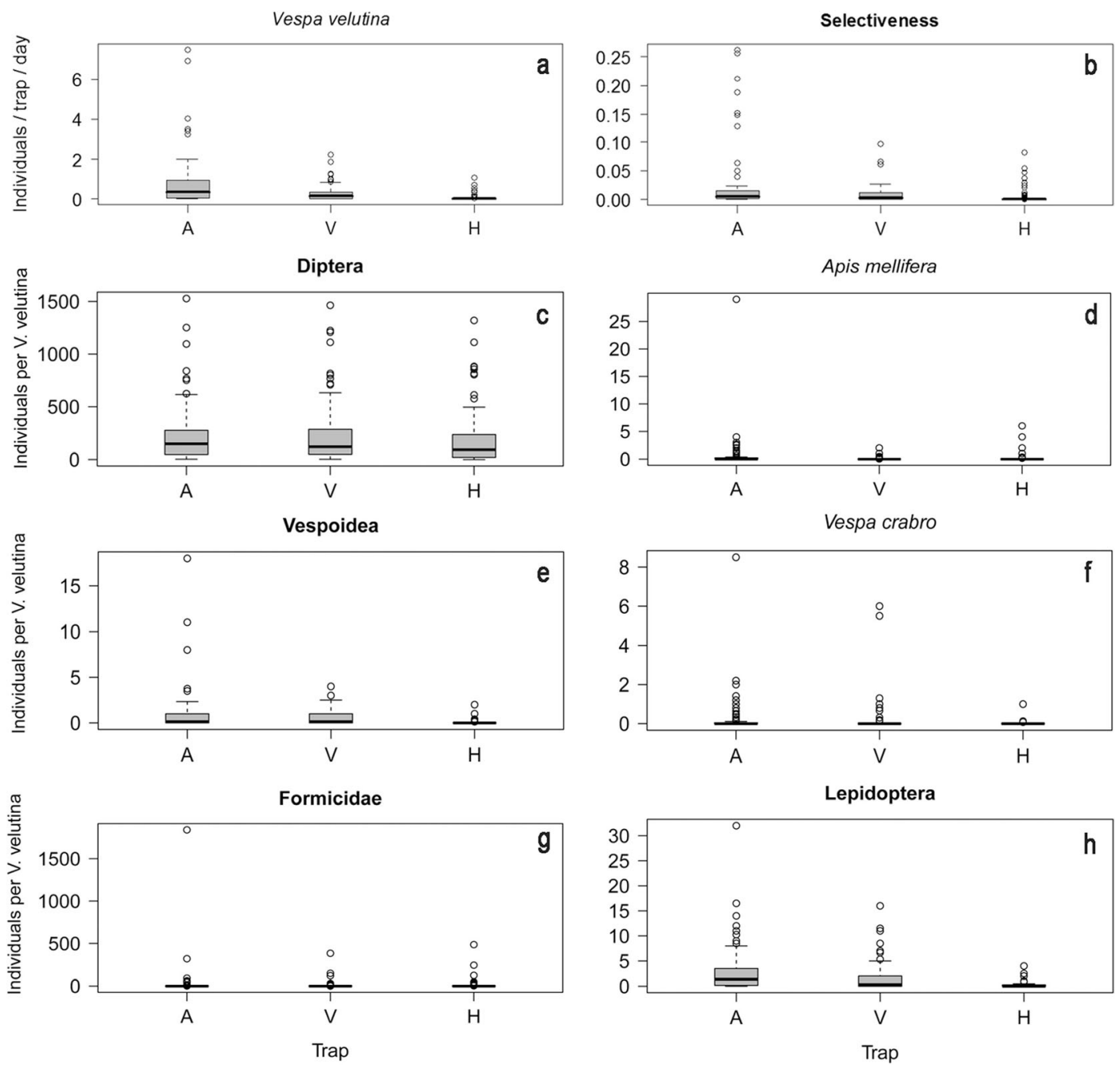

Figure 3. Effectiveness (a) and selectiveness (b) of three traps tested for the capture of V. velutina . Ratio between the number of individuals of non-target taxa and individuals of $V$. velutina for groups of insects commonly captured (c-h ). Abbreviations: A, Avispa'clack trap; V, Véto-pharma trap; H, home-made (funnel) trap. Box plots represent medians (horizontal bold lines), quartiles (boxes), 2.5-97.5 percentiles (vertical lines), and outliers (open circles).

\section{DISCUSSION}

\subsection{Capture rate and selectiveness of baited traps}

The results highlight the relevance of the design and placement of traps as key parameters to optimize captures of queens of the invasive hornet $V$. velutina. Commercial traps had higher effectiveness than home-made $(\mathrm{H})$ traps, especially A traps. $\mathrm{H}$ traps were the less selective despite that the small lateral holes allow small insects to escape. Because of their bigger size, A traps use 1.5 times more bait than the other traps, but they achieve more than 1.5 higher performance compared to the other trap types, both in terms of capture rate and also selectiveness. Besides, A traps differ not only in the amount of bait, but also in the shape and size of the chamber and the position of the entrance. A bigger chamber allows drowning and accumulation of more individuals with a lower impact on the strength of the scent 
Table IV. Results from (GLMM) analysis for the selectiveness of baited traps (measured as the number of $V$. velutina individuals divided by the total number of individuals captured per trap and per day) to capture the target taxa.

\begin{tabular}{lccc}
\hline Factor & d.f. & $\begin{array}{l}\text { Deviance } \\
\left(\chi^{2}\right)\end{array}$ & $\begin{array}{c}p \\
\text { value }\end{array}$ \\
\hline Trap & 2 & 6.32 & $0.042^{*}$ \\
Bait & 2 & 2.26 & 0.324 \\
Trap:Bait & 4 & 0.47 & 0.976 \\
Proximity to apiaries & 1 & 9.301 & $0.002^{*}$ \\
$\begin{array}{l}\text { Proximity to bodywaters } \\
\text { Trap: proximity to }\end{array}$ & 1 & 2.73 & 0.099 \\
$\quad$ bodywaters & 2 & 4.44 & 0.976 \\
Land use & 2 & 0.98 & 0.612 \\
\hline
\end{tabular}
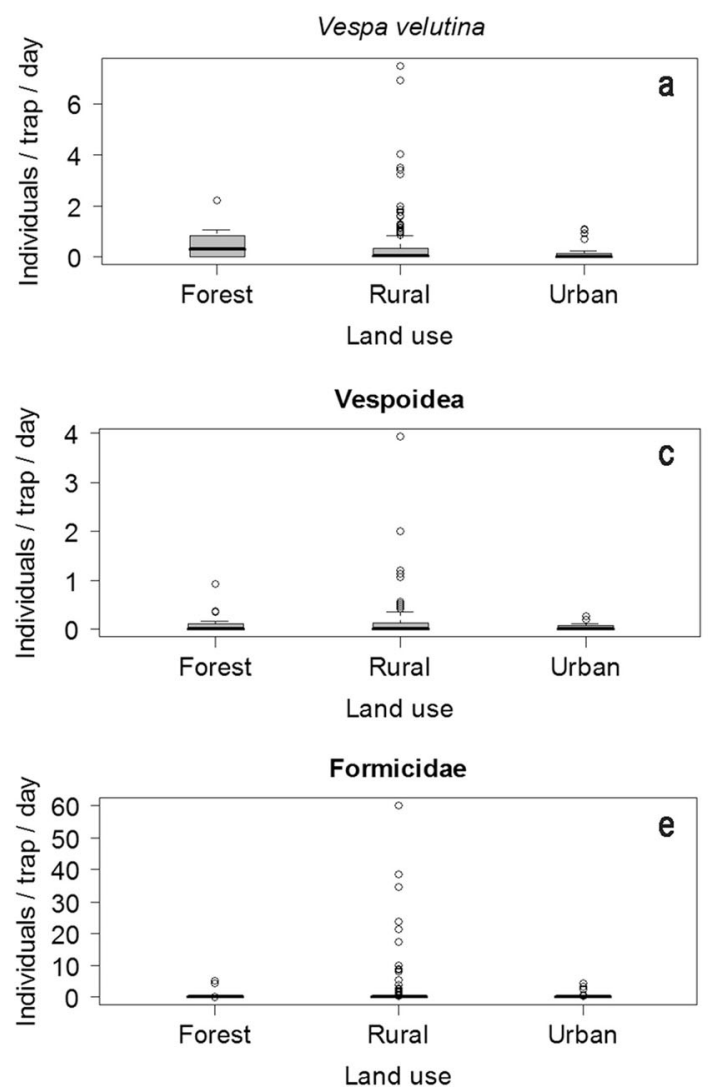

signal compared to smaller traps. However, this cannot explain the higher selectiveness of this trap type. Either the position of the entrance (in the bottom instead of the upper part), the size of the hole that allows a higher evaporation rate of bait and therefore emanates a higher amount of scent signal or the shape and the color of this trap make it more effective in capturing $V$. velutina . Interestingly, commercial and home-made baits had similar performance, both in terms of effectiveness and selectivity, and their performance did not differ depending on the trap.

Traps with chemical attractants are broadly used as a control tool for the capture of invasive wasps (Landolt 1998; Beggs et al. 2011). The results in this study show relative low capture rates of $V$. velutina in baited traps, which agrees with previous assessments, despite differences
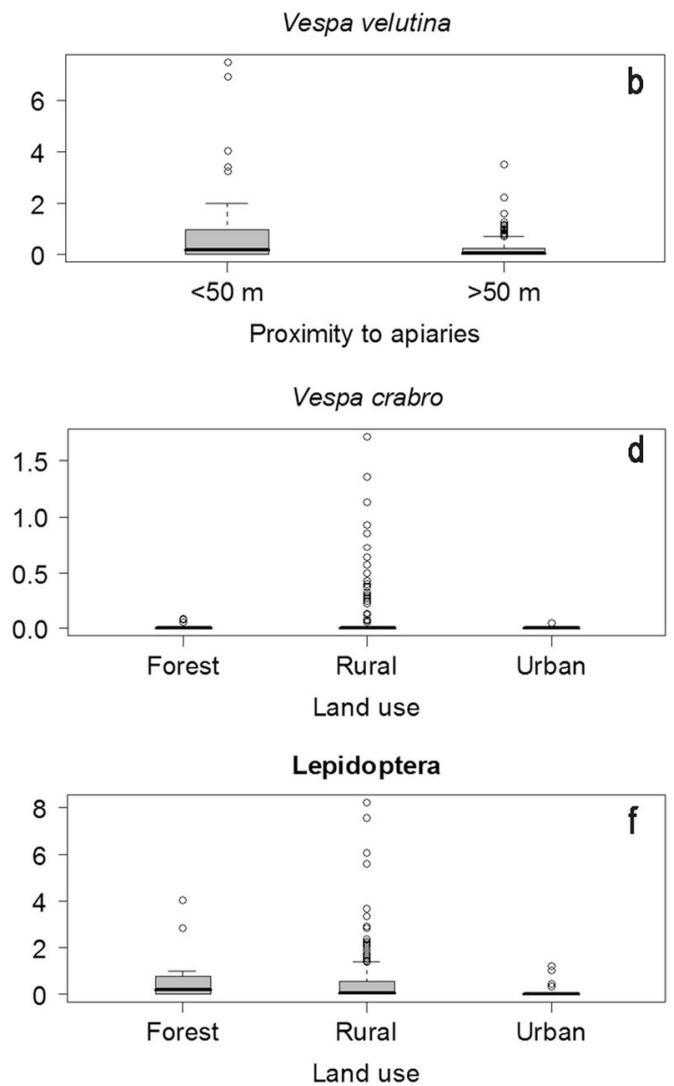

Figure 4. Capture rates of $V$. velutina $(\mathbf{a}, \mathbf{b})$ and non-target taxa $(\mathbf{c}-\mathbf{f})$ under several environmental factors. Box plots represent medians (horizontal bold lines), quartiles (boxes), 2.5-97.5 percentiles (vertical lines), and outliers (open circles). 
among studies in trap design, bait composition, sampling seasons, and sites (Dauphin and Thomas 2009; Rome et al. 2011b; Monceau et al. 2013b; Goldarazena et al. 2015). In regions recently invaded or during the queen colony phase, it is expectable to have a low capture rates because of the lower number of individuals in the environment in comparison with regions with a long story of invasion during the summer season. However, according to previous studies made in different regions and seasons, capture rates of $V$. velutina with baited traps or its proportion in comparison with non-target taxa are low to intermediate, even in summer and when nests reach maximal size and workers are very active in the field (see Monceau et al. 2012; Monceau et al. 2013b; Decante 2015).

In order to determine the effectiveness of trapping campaigns to control $V$. velutina, a comprehensive assessment of the actual impact on its populations is urgently needed. However, little is known at the moment in this regard. Monceau et al. (2012) estimated the probable number of founding queens capable of initiating a nest in the spring in one region, 111 queens, and compared this number with the number of queens trapped in the same area during the spring, 26 queens. That is, they captured $23.4 \%$ of the potential founders. Although this percentage is not negligible, the method cannot be considered as effective and probably requires a combination with other tools implemented at the long term to cause considerable reductions of the species (see Robinet et al. 2017). Also, the number of founding queens initiating a nest in spring is probably variable among regions and years according to climatic conditions, resource availability, and survivorship or usurpation rates (Gamboa 1978; MacDonald and Matthews 1981; Archer 2012). Broad scale studies are needed to quantify the actual efficiency of trapping campaigns for reducing the population of $V$. velutina to evaluate its sustainability as a control method and facilitate decisions by policy makers. However, with the traps and baits currently used, the populations of native insects can be threatened by trapping campaigns. Particularly to those insects which are frequently trapped but that are not common prey of $V$. velutina such as $V$. crabro, Lepidoptera, or Coleoptera (Table II). Also, Diptera are commonly captured in baited traps (80-95\% according to land use, assessed in this study), but less frequently hunted by $V$. velutina (17-34\% according to land use, see Villemant et al. (2011b)). Apidae and Vespidae had the contrary tendency $(0.93-0.27 \%$ captured in traps vs. 33$65 \%$ hunted; and $1.2-1.3 \%$ captured in traps vs. $7.8-28 \%$ hunted, respectively). This comparison is informative about the tendencies, but must be taken with care since the data were obtained for different regions and years and the relative abundances of taxa can vary between them.

\subsection{Environmental factors that affect capture rates of Vespa velutina}

Traps placed in forest areas and near apiaries were the most effective for the capture of $V$. velutina queens in spring. The higher capture success in forested areas can be related to differences in the availability of resources (food, nest materials, insects), which has been suggested as broad scale drivers of invasion (Bessa et al. 2016). It could also reflect that there is a higher abundance of queens that hibernate and survive in this habitat since they can find more suitable places to overwinter and be protected by vegetation in harsh environmental conditions (Edwards 1980; Matsuura and Yamane 1990; Vetter and Visscher 1997). The higher capture success achieved next to apiaries suggests that queens are attracted to honeybee colonies. This finding differs with a previous study where it is suggested that it is not necessary to protect the apiary in spring in invaded areas, based on the fact that captures of $V$. velutina in the vicinity of apiaries were very low (Monceau et al. 2012). Indeed, in previous years, queens were not frequently seen hunting in beehives at the beginning of the spring. However, in the region of the present study during the last years, they began to hunt in apiaries very early in the season even when no baited traps were placed near the apiaries (pers. obs.). This can be related to the capacity of $V$. velutina to be attracted toward particular compounds present in pollen, honey, and honeybees' pheromones (Rome et al. 2011a; Couto et al. 2014). These findings can be used to enhance control plans using honey bee scents as component of selective lures. 
Previous studies stress the relevance of the proximity to bodies of water as key parameters for trapping and nest location (Monceau et al. 2012; Bessa et al. 2016). However, this study does not reveal a significant effect of this factor on the capture rates of $V$. velutina queens. The study area, the coastal part of Galicia, is rainy in spring and drained by numerous rivers and streams, facilitating hornets to find water sources virtually everywhere, which would explain the low significance of this factor. In addition, small sources of water, such as small pools, ponds, trough, or irrigation channels, which were not considered in our study due to its geographic broad scale, can be enough for the development of colonies. In spring, the colonies are small and so are their resource requirements. Further in the season, the growing of the colony conduce to an increase in the requirements of food, water, and other resources in summer, at the same time that water becomes less abundant. It is then when the proximity to water sources could become a limiting factor contributing to stagnation, collapse, or relocation of the colony.

\subsection{Groups of native insects affected by trapping campaigns}

The comparative better performance of A traps in terms of capture rate of $V$. velutina and selectiveness must be considered with caution. This trap also captured higher rates of non-target insects, including dipterans, honeybees, and other hymenopterans. In particular, its wider entrance allows the access of bigger-bodied species, such as lepidopterans and the native hornet $V$. crabro, compared with traps with smaller entrances. Captures of $V$. crabro must be avoided for several reasons. First, because it is a native species listed as endangered or protected in some European areas such as Germany (http://www.gesetze-iminternet.de/bartschv_2005/anlage_1.html) or Austria (https://www.ris.bka.gv.at). Also, considering the phylogenetical and biological similarities with $V$. velutina, it is probably one of the species likely to compete with the invasive hornet for resources (Monceau et al. 2015). Therefore, it has the potential to counteract naturally, to some degree, the expansion of $V$. velutina . Further research regarding the interaction between these congeneric species is needed to clarify the effects that one species has on the other one.

According to the capture rates of non-target species recorded in our study, spring control campaigns against $V$. velutina could result in significant impacts on insect populations. Groups such as Diptera, different Hymenoptera, Lepidoptera, and Coleoptera are attracted by baits and odors of dead bodies in traps. Other studies recording insects captured in traps for $V$. velutina in diverse regions report similar results: during spring and autumn, high quantities of Dipterans, Lepidopterans and Coleopterans are commonly trapped in France (Dauphin and Thomas 2009; Haxaire and Villemant 2010; Rome et al. 2011b; Monceau et al. 2012), while Diptera, Lepidoptera, and Hymenoptera were the most common insects recorded in Northeast Spain during summer and autumn (Goldarazena et al. 2015).

The use of baited traps is often justified by the argument of "killing one queen in spring will protect many insects that the colony (founded by this queen) would hunt in summer and autumn." Considering the identity of insects hunted by V. velutina (Villemant et al. 2011b), probably the honey bee (A. mellifera) is the most favored species with trapping, as it is highly predated by $V$. velutina but capture rate in baited traps is relatively low. Other groups such as dipterans, vespids, and other hymenopterans benefit to a lesser extent, since they are more frequently captured by $V$. velutina (at least considering broad taxonomic levels). However, there are other groups of insects such as Coleoptera, Lepidoptera, Vespa crabro, and Bombus sp. that are not commonly hunted by $V$. velutina, but that frequently fall into baited traps (Table II). For these groups, the impact of trapping can be significantly negative, endangering populations in entire regions. These findings support the growing body of evidence which indicates that baited traps currently being used to reduce the invasive population represent a potential threat for the native fauna added to the direct impact of $V$. velutina as a predator.

\section{CONCLUSION}

The low capture rate and selectiveness of baited traps currently used together with the high 
colonization ability of $V$. velutina and the high mortality caused on non-target insect groups, particularly some that are not common prey of the invasive species, questions the utility of this method as a control tool. There is an urgent need for improving both attractants and trap designs. This study shows that commercial baits do not exhibit significant improvements compared to homemade baits. Trap designs, however, probed to mark differences both in terms of effectiveness and selectiveness, with commercial designs showing better results than the home-made design tested. Caution however is advisable, since the most effective and selective design tested (Avispa' clac) showed high rates of capture of sensitive species such as some lepidopterans, especially moths, and V. crabro. Research in improving trap designs appear as a promising field for advancement, aiming at enhancing capture rates of $V$. velutina and, above all, selectiveness, in order to minimize impacts on native entomofauna.

\section{ACKNOWLEDGMENTS}

This work was supported by the European Innovation Partnerships - EU Framework Programme for Research and Innovation (H2020) through the creation of the Operative Group Vespa velutina. We thank beekeepers of Asociación Galega de Apicultura for the financial support and help with field work. X. Asorey and $\mathrm{X}$. Feás contributed to the experimental design.

\section{AUTHOR CONTRIBUTION}

SRN and MCC conceived the research, participated in the analysis, and wrote and reviewed the paper. SRN, NN, and AS performed experiments. All authors read and approved the final manuscript.

\section{COMPLIANCE WITH ETHICAL STANDARDS}

Conflict of interest The authors declare that they have no conflict of interest.

Performances des pièges à appâts utilisés comme outils de lutte contre le frelon invasif Vespa velutina et leur impact sur les insectes non ciblés
Apiculture / Apis mellifera / espèces envahissantes / outils de lutte antiparasitaire / frelon asiatique

Wirksamkeit von Lockstofffallen zur Bekämpfung der invasiven Hornisse Vespa velutina und ihre Wirkung auf Nicht-Ziel-Insekten

Bienenhaltung / Apis mellifera / invasive Arten / Hilfsmittel zur Schädlingsbekämpfung / asiatische Hornisse

\section{REFERENCES}

Arca M, Mougel F, Guillemaud T et al (2015) Reconstructing the invasion and the demographic history of the yellow-legged hornet, Vespa velutina, in Europe. Biol Invasions 17: 2357-2371

Archer, ME (2010) The queen colony phase of vespine wasps (Hymenoptera, Vespidae). Insect Soc 57: 133-145

Archer ME (2012) Vespine wasps of the world. Behaviour, ecology and taxonomy of the Vespinae. Monograph series. Siri Scientific Press, Manchester

Beggs JR, Brockerhoff EG, Corley JC, Kenis M, Masciocchi M, Muller F, Rome Q, Villemant C (2011) Ecological effects and management of invasive alien Vespidae. BioControl 56: 505-526

Bessa AS, Carvalho J, Gomes A, Santarém F (2016) Climate and land-use drivers of invasion: Predicting the expansion of Vespa velutina nigrithorax into the Iberian Peninsula. Insect Conserv Diver $9: 27-37$

Burnham K, Anderson D (2002) Model Selection and Multimodel Inference. A Practical InformationTheoretic Approach, 2nd edn. Springer, New York

Choi MB, Martin SJ, Lee JW (2012) Distribution, spread, and impact of the invasive hornet Vespa velutina in South Korea. J Asia-Pac Entomol 15 :473-477

Ciron J, Mathis S, Iljicsov A, Boucebci S, Neau JP (2015) Multiple simultaneous intracranial hemorrhages due to hornet stings. Clin Neurol Neurosur 128:53

Couto A, Monceau K, Bonnard O, Thiéry D, Sandoz JC (2014) Olfactory attraction of the hornet Vespa velutina to honeybee colony odors and pheromones. PLOS ONE 9 :1-19

Dauphin P, Thomas H (2009) Quelques données sur le contenu des pièges à frelons asiatiques posés à Bordeaux (Gironde) en 2009. Bull Soc Linn Bordeaux 144 :287-297

de Haro L, Labadie M, Chanseau P, Cabot C, Blanc-Brisset I, Penouil F (2010) Medical consequences of the Asian black hornet (Vespa velutina) invasion in Southwestern France. Toxicon $55: 650-652$

Decante D (2015) Lutte contre le frelon asiatique Vespa velutina - Evaluation comparative des modalités de piégeage de protection du rucher. ITSAP. http://www. 
itsap.asso.fr/downloads/publications/cr evaluation piegeage_vvelutina_2014_vdef.pdf. Āccessed 1 $\overline{1}$ June 2018

Demichelis S, Manino A, Minuto G, Mariotti M, Porporato M (2014) Social wasp trapping in north west Italy: Comparison of different bait-traps and first detection of Vespa velutina. B Insectol $67: 307-317$

Edwards R (1980) Social wasps. Their behaviour and control. Rentokil Limited, Sussex

EPPO (2016) First report of Vespa velutina in the United Kingdom. Reporting Service No 11 - 2016, Num article: 2016/208. https:/gd.eppo.int/reporting/article5953. Accessed 11 June 2018

Fitzgerald KT, Flood AA (2006) Hymenoptera stings. Top Companion Anim M $21: 194-204$

Fournier A, Barbet-Massin M, Rome Q, Courchamp F (2017) Predicting species distribution combining multi-scale drivers. Glob Ecol Conserv 12 : 215-226

Gamboa GJ (1978) Intraspecific defense: Advantage of social cooperation among Paper wasp foundresses. Science 199 : $1463-1465$

Goldarazena A, Heredia IP, Romon P, Iturrondobeitia JC, Gonzalez M, Lopez S (2015) Spread of the yellowlegged hornet Vespa velutina nigrithorax du Buysson (Hymenoptera: Vespidae) across Northern Spain. Bull OEPP 45: 133-138

Haxaire J, Villemant C (2010) Impact sur l'entomofaune des pièges à Frelon asiatique. Insectes $4: 1-6$

Haxaire J, Bouguet J-P, Tamisier J-P (2006) Vespa velutina Lepeletier, 1836, une redoutable nouveauté pour la faune de France (Hym, Vespidae). Bull Soc Entomol Fr $111: 194$

INPN (Inventaire National du Patrimoine Naturel) (2018) Le Frelon asiatique Vespa velutina. http://frelonasiatique. mnhn.fr/home/. Accessed 07 June 2018

Landolt PJ, Tóth M, Jósvai J (2007) First European report of social wasps trapped in response to acetic acid, isobutanol, 2-methyl-2-propanol and heptyl butyrate in tests conducted in Hungary. B Insectol $60: 7-11$

Landolt PJ (1998) Chemical attractants for trapping Yellowjackets Vespula germanica and Vespula pensylvanica (Hymenoptera: Vespidae). Environ Entomol 27: 1229-1234

Liu Z, Chen S, Zhou Y, et al (2015) Deciphering the venomic transcriptome of killer-wasp Vespa velutina . Sci Rep $5: 9454$

MacDonald JF, Matthews RW (1981) Nesting biology of the eastern Yellowjacket, Vespula maculifrons (Hymenoptera: Vespidae). J Kansas Entomol Soc 54 :433457

Matsuura M, Yamane S (1990) Biology of vespine wasps. Springer-Verlag, Berlin

Monceau K, Thiéry D (2017) Vespa velutina nest distribution at a local scale: An 8-year survey of the invasive honeybee predator. Insect Sci $24: 663-674$

Monceau K, Maher N, Bonnard O, Thiéry D (2015) Evaluation of competition between a native and an invasive hornet species: Do seasonal phenologies overlap? B Entomol Res 105 :462-469

Monceau K, Arca M, Leprêtre L, Florence M, Bonnard O, Silvain J-F, Maher N and Thiéry D (2013a) Native Prey and invasive predator patterns of foraging activity: The case of the Yellow-legged hornet predation at European honeybee hives. PLoS ONE 8:1-9

Monceau K, Bonnard O, Thiéry D (2012) Chasing the queens of the alien predator of honeybees: A water drop in the invasiveness ocean. Open J Ecol 2: 183-191

Monceau K, Bonnard O, Thiéry D (2014) Vespa velutina: A new invasive predator of honeybees in Europe. $\mathrm{J}$ Pest Sci $87: 1-16$

Monceau K, Maher N, Bonnard O, Thiéry D (2013b) Predation pressure dynamics study of the recently introduced honeybee killer Vespa velutina: Learning from the enemy Apidologie 44: 209-221

Pérez-de-Heredia I, Darrouzet E, Goldarazena A, Romón P, Iturrondobeitia JC (2017) Differentiating between gynes and workers in the invasive hornet Vespa velutina (Hymenoptera, Vespidae) in Europe. J Hymenopt Res 60: 119-133

Perrard A, Haxaire J, Rortais A, Villemant C (2009) Observations on the colony activity of the Asian hornet Vespa velutina Lepeletier 1836 (Hymenoptera: Vespidae: Vespinae) in France. Ann Soc Entomol Fr 45:119-127

Robinet C, Suppo C, Darrouzet E (2017) Rapid spread of the invasive yellow-legged hornet in France: The role of human-mediated dispersal and the effects of control measures. J Appl Ecol 54 :205-215

Rome Q, Muller F, Théry T, Andrivot J, Haubois S, Rosenstiehl E, Villemant C (2011a) Impact sur l'entomofaune des pièges à bière ou à jus de cirier utilisés dans la lutte contre le frelon asiatique. In: Barbançon J-M (ed) Proceedings of the Journée Scientifique Apicole - 11 February 2011, Arles ONIRIS-FNOSAD, Nantes, pp 18-20

Rome Q, Muller F, Théry T, Andrivot J, Haubois S, Rosenstiehl E, Villemant C (2011b) Monitoring and control modalities of a honeybee predator, the Yellowlegged hornet Vespa velutina nigrithorax (Hymenoptera: Vespidae). Newsletter of the IUCN/SSC Invasive Species Specialist Group $31: 7-15$

Rome Q, Muller FJ, Touret-Alby A, Darrouzet E, Perrard A, Villemant C (2015) Caste differentiation and seasonal changes in Vespa velutina (Hym: Vespidae) colonies in its introduced range. J Appl Entomol 139:771-782

Rortais A, Villemant C, Gargominy O, Rome Q, Haxaire J, Papachristoforou A, Arnold G (2010) A new enemy of honeybees in Europe: the Asian hornet Vespa velutina . In: Settele J (ed) Atlas of biodiversity risks- from Europe to the globe, from stories to maps, Pensoft, Sofia, pp 11

Sciences Switzerland (2017) The Asian hornet reaches Switzerland. https://naturalsciences. ch/service/news/90430-the-asian-hornet-reaches-switzerland. Accessed 11 June 2018

Skaug H, Fournier D, Nielsen A, Magnusson A, Bolker B (2011) glmmADMB: Generalized Linear Mixed 
Models Using AD Model Builder R Package, version 07. http://glmmadmb.r-forge.r-project.org, http://admb-project.org

Spradbery JP (1973) Wasps: An Account of the Biology and Natural History of Social and Solitary Wasps. University of Washington Press, Seattle

Tabar AI, Chugo S, Joral A, et al (2015) Vespa velutina nigritorax: a new causative agent for anaphylaxis. Clin Transl Allergy $5: 43$

Tan K, Radloff SE, Li JJ, Hepburn HR, Yang MX, Zhang LJ, Neumann P (2007) Bee-hawking by the wasp, Vespa velutina, on the honeybees Apis cerana and A mellifera. Naturwissenschaften 94, 469-472

Toft RJ, Harris RJ (2004) Can trapping control Asian paper wasp (Polistes chinensis antennalis) populations? New Zeal J Ecol 28 :279-282

Ueno T (2014) Establishment of the invasive hornet Vespa velutina (Hymenoptera : Vespidae) in Japan. Int J Chem Environ Biol Sci 2 :220-222

Venables WN, Ripley BD (2002) Modern Applied Statistics with S, 4th edn. Springer, New York

Vetter RS, Visscher PK (1997) Plasticity of annual cycle in Vespula pensylvanica shown by a third year polygynous nest and overwintering of queens inside nests. Insect Soc 44:353-364

Villemant C, Barbet-Massin M, Perrard A, Muller F, Gargominy O, Jiguet F, Rome Q (2011a) Predicting the invasion risk by the alien beehawking Yellow-legged hornet Vespa velutina nigrithorax across Europe and other continents with niche models. Biol Conserv $144: 2142-2150$

Villemant C, Muller F, Haubois S (2011b) Bilan des travaux (MNHN et IRBI) sur l'invasion en France de Vespa velutina, le frelon asiatique prédateur d'abeilles. In: Barbançon J-M, L'Hostis M (eds) Proceedings of the Journée Scientifique Apicole, Arles, Nantes, pp 3-12

Viriot D, Sinno-Tellier S, de Haro L (2015) Ce frelon asiatique qui fait si peur: quoi de neuf en urgence? Toxicol Anal Clin 27: S30

Wegner G, Jordan K (2005) Comparison of three liquid lures for trapping social wasps (Hymenoptera: Vespidae). J Econ Entomol 98 :664-666

Witt R (2015) Erstfund eines Nestes der Asiatischen Hornisse Vespa velutina Lepeletier, 1838 in Deutschland und Details zum Nestbau (Hymenoptera, Vespinae) Ampulex 7:42-53 